\title{
BANKING REGULATION AND PROMPT CORRECTIVE ACTION
}

\author{
XAVIER FREIXAS \\ BRUNO M. PARIGI
}

CESifo Working PAPER No. 2136
Category 6: Monetary Policy And InTERnational Finance
November 2007
Presented at CESifo Area Conference on Appled Microeconomics, March 2007

An electronic version of the paper may be downloaded

- from the SSRN website:

www.SSRN.com

- from the RePEc website:

- from the CESifo website:

www.RePEc.org

www.CESifo-group.org/wp 


\title{
BANKING REGULATION AND PROMPT CORRECTIVE ACTION
}

\begin{abstract}
We explore the rationale for regulatory rules that prohibit banks from developing some of their natural activities when their capital level is low, as epitomized by the US Prompt Corrective Action (PCA). This paper is built on two insights. First, in a moral hazard setting, capital requirement regulation may force banks to hold a large fraction of safe assets which, in turn, may lower their incentives to monitor risky assets. Second, agency problems may be more severe in certain asset classes than in others. Taken together, these two ideas explain why, surprisingly, capital regulation, which may cope with risk and adverse selection, is unable to address issues related to moral hazard. Hence, instead of forcing banks to hold a large fraction of safe assets, prohibiting some types of investment and allowing ample scope of investment on others may be the only way to preserve incentives and guarantee funding. In particular, providing incentives to monitor investments in the most opaque asset classes may prove to be excessively costly in terms of the required capital and thus inefficient. We show that the optimal capital regulation consists of a rule that a) allows well capitalized banks to freely invest any amount in any risky asset, b) prohibits banks with intermediate levels of capital to invest in the most opaque risky assets, and c) prohibits undercapitalized banks to invest in any risky asset.
\end{abstract}

JEL Code: E58, G21.

Keywords: banking, prudential regulation, moral hazard.

Xavier Freixas

Department of Economics and Business

University Pompeu Fabra

Ramon Trias Fargas 25 - 27

08005 Barcelona

Spain

xavier.freixas@econ.upf.es
Bruno M. Parigi

Department of Economics

University of Padova

Via del Santo 33

35123 Padova

Italy

brunomaria.parigi@unipd.it

October 19, 2007 


\section{Introduction}

The aim of this paper is to understand the logic behind the US banking regulation called Prompt Corrective Action (PCA). PCA was introduced in 1991 by the Federal Deposit Insurance Corporation Improvement Act (FDICIA) in response to the banking crises of the 1980s to integrate capital regulation with the main goal to preclude supervisory forbearance (Calem and Rob 1999).

The definition of banks' permitted range of activities is traditionally part of bank regulation. What is original about PCA is that it places mandatory restrictions on bank's activities depending on capital ratios. ${ }^{1}$ Banks are classified in 5 categories depending on (various measures of) capital ratios: for example, well capitalized, with capital ratio (total risk-based capital) $\geq 10 \%$; Adequately capitalized $\geq 8 \%$; Undercapitalized $<8 \%$; Significantly Undercapitalized $<6 \%$; Critically Undercapitalized $\leq 2 \%$ of tangible equity. Well capitalized and adequately capitalized banks face no restrictions; banks in the three bottom categories face restrictions which become more and more severe the lower their capital ratios.

Examples of the restrictions to banks' actions are: limits to dividends payments and compensation to senior managers; increased monitoring; restrictions to asset growth; restrictions to interaffiliate transactions; required authorization for acquisitions and new business lines; required authorization to raise additional capital; limits to credit for highly leveraged transactions; and in the most extreme cases, receivership. A key aspect of PCA is that it specifies a mix of discretionary and mandatory provisions for institutions in each category rather than relying only on regulatory discretion (Benston and Kaufman 1997).

In a context where the scope of banking activities has been expanding, with the repeal of the Depression-era banking legislations both in the US and in some European countries, banks engage in a wider range of activities, and banking operations growing in complexity due to fundamental

\footnotetext{
${ }^{1}$ Here we just sketch the main features of PCA. For a detailed description of its functioning we refer to e.g. Jones and King (1995) and Benston and Kaufman (1997).
} 
changes in the financial industry, the issue of the benefits of a PCA-type of legislation in countries outside the US is timely and relevant, from the perspective both of prudential regulation and of the efficiency of the banking industry.

Introducing regulation similar to PCA is complex, as it requires an important amendment both to the bankruptcy code and to the law delegating powers to the regulator. With the existing law its implementation is impossible in Europe and in the majority of countries, and it is not part of Basle's "Core Principles for Effective Banking Supervision". Yet, the benefits of PCA seem to be impressive, as individual bank crises are replaced by low cost open-bank resolution. Thus, understanding the cost-benefit analysis of PCA and assessing whether this piece of regulation should be exported to other countries has been a key motivation of our research. Since there is no model of the impact of PCA, the objective of this paper is to develop a model that allows us to identify and assess the effects of PCA.

Although intuitively the benefits of PCA are obvious, its modelling may be challenging. Indeed, it may seem reasonable, prima facie, to restrict a bank's risky activities as its capital is depleted. But to achieve that goal the standard capital regulation with appropriate risk weights should suffice. So, the issue is more involved and requires a careful distinction between risk and asymmetric information.

The novelty of our analysis stems from the observation that the complexity of many bank's investments per se, independently from risk, is a source of agency problems that cannot be addressed solely by means of quantitative capital regulation; instead a combination of qualitative and quantitative restrictions succeeds in providing efficient regulation.

Thus, our approach goes beyond the view that justifies capital as a buffer against losses and hence failure (Dewatripont and Tirole 1994). It also departs from the view that capital lowers risktaking (Rochet 1992) and aligns the incentives of bank owners with those of depositors and other 
creditors. These views constitute the core of what we see as the traditional approach, even if there might be dissenting perspectives. ${ }^{2}$

Although from a completely different standpoint, our paper shares with Calem and Rob (1999) the result of establishing the limitations of capital regulation. Calem and Rob find that the amount of risk a bank takes depends on its level of capital, with the most severely undercapitalized banks taking on maximal risk. As capital increases banks take less risk, and as capital rises further banks take more risk. Calem and Rob (1999) argue that this U-shaped relationship between capital position and risk-taking is a serious drawback to the usefulness of capital regulation, and that instead it provides a rationale for the PCA provision of FDICIA.

A recent strand of theoretical and empirical literature on the role of capital in banks makes two points that are quite relevant for our analysis: first, market forces exert a prominent influence on bank leverage decisions; second, this literature challenges the assumption that banks holds as little capital as possible. In particular two studies have noted that capital ratios are strategic variables in bank competition. Kim et al. (2005) using a sample of Norwegian banks show that banks can use capital ratios to differentiate their services and soften competition. Allen et al. (2005) link capital regulation to the competition banks face in the credit market. When banks compete for projects because there is an excess supply of funds relative to investment opportunities, market discipline may be so strong to impose a level of capital higher than that imposed by the regulator. Flannery and Rangan (2004) document that book capital ratios at the 100 largest U.S. Bank Holding Companies (BHC) have raised substantially in the period between 1986 and 2000. The average bank has always exceeded the minimum required capital ratio, and the percentage of constrained BHC dropped to the point that capital restrictions became effectively non-binding for the 100 largest US BHC after 1992. They find support to the hypothesis that large banks' capital growth

\footnotetext{
${ }^{2}$ Other studies argue that capital requirements may have the unintended effect of increasing risk-taking behavior because of the loss of franchise value (Helmann, Murdock, Stiglitz 2000), and the compounding of moral hazard in effort and risk choice (Besanko and Kanatas 1996). Gorton and Winton (2003) question both the very notion that moral hazard induces banks to take on excessive risk, and the resulting rationale for capital regulation.
} 
has been a deliberate response to market changes making bank counterparties more sensitive to the default risk of banks. As a result banks increased their capital ratios to lower their funding costs.

The literature on PCA is mainly empirical. Since the introduction of PCA there have been several attempts to assess its functioning. The consensus is that it has worked well: in particular PCA has had a significant impact both in terms of raising capital ratios and reducing risk for banks (e.g. Benston and Kaufmann 1997, Aggarwal and Jaques 2001, Elizalde and Repullo 2006). Two theoretical papers on PCA are particularly relevant for our work. Both focus on the optimal closure policy of banks hit by shocks but not on the benefits of restricting banking activities depending on their capital level. In Shim (2004) the banker can divert profits and affect risk and return. In a dynamic game between the deposit insurance regulator and the banker it is optimal to base the regulation on the level of capital and to use a stochastic termination threat to induce the banker to exert effort and to report income truthfully. In Kocherlakota and Shim (2005) loans repayment are enforced only through risky collateral. The optimal contract among firms, depositors, and taxpayers has bank termination or forbearance depending on the ex ante probability that taxpayers' money is involved. $^{3}$

Pelizzon and Schaefer (2005) construct a model of the interaction of the capital requirement (Pillar 1) and supervision (Pillar 2) under the New Basel Accord. They find that if capital requirements can be enforced only through audit and if in its absence the bank faces no constraint on its portfolio, then regulatory interventions in the form of forced recapitalization or closure, possible under Pillar 2, have a role. In this view Pillar 2 is similar to the concept of PCA in the US.

All these papers enhance our understanding of optimal capital regulation of banks, but they do not justify the existence of qualitative restrictions to bank actions which is the key feature of PCA. The object of our research is precisely to construct a model of banking regulation that

\footnotetext{
3 Modeling optimal bank capital regulation in a dynamic context is related to the study of dynamic optimal corporate capital structure. Biais et al. (2006) consider a model of corporate finance where the manager can divert income, and show that the infinite repetition of the game between financiers and manager, where the firm is downsized when it runs out of cash, provides appropriate incentives to the manager.
} 
combines two types of restrictions on bank investments. The first one corresponds to forcing the bank to hold a minimum fraction of safe assets (which is very similar to capital requirements). The second one imposes restrictions to the types of risky assets the bank is allowed to invest in.

Our paper is built on two insights. First, in a moral hazard setting, forcing banks to hold a large fraction of safe assets may lower their incentives to exert effort to monitor risky assets; i.e. it is necessary to guarantee the banks enough profits to recover monitoring costs. Hence instead of forcing the bank to hold a large fraction of safe assets, prohibiting certain types of investment and allowing ample scope of investment on others may be the only way to preserve incentives. Second, it is well known that bank assets are generally opaque precisely because banks specialize in lending to information-sensitive customers; however, opacity, and hence agency problems, may be more severe in certain asset classes than in others. Providing incentives to monitor investments in the most opaque asset classes may thus be more costly in the sense that these investments can pay out less cash flow and require more capital. Prohibiting some activities could thus allow the bank to have better access to funding it would have been deprived of because of moral hazard.

Our main finding is that a regulator aiming to maximize the expected value produced by the banking industry should restrict the composition of a bank portfolio according to the following capital ratio rule: the regulator should a) allow well capitalized banks to invest any amount in any risky asset, b) prohibit banks with intermediate levels of capital to invest in the most opaque risky assets, and c) prohibit undercapitalized banks to invest in risky assets at all. This rule captures in a stylized fashion one of the key features of the PCA regulation adopted in the US, namely the notion that restrictions to bank assets becomes more stringent the less capitalized banks are. Notice that these restrictions could not have been replicated with standard risk-adjusted capital regulation, except if, by coincidence, the riskyness of loans and the moral hazard possibilities are perfectly aligned.

Finally we use our basic framework to analyze the adjustment of the scale of bank operations to address regulatory concerns. We show that for a given level of capital the regulator 
can exploit a trade-off between the scope of bank operations (the set of allowed investments) and the scale of bank assets.

The rest of the paper is organized as follows. In section 2 we set up the basic model of investment under moral hazard with fixed bank size. In section 3 we analyze the functioning of the unregulated banking industry. In section 4 we introduce PCA and determine the optimal regulation. In section 5 we extend the main result to the variable bank size, and in section 6 we conclude.

\section{Model set up}

We consider a static model of bank investments with a risk-neutral bank owner-manager. Bank asset size is fixed and normalized to 1 . In Section 5 we consider the general case with variable bank size. Assets are funded by bank capital, $K<1$, and by uninsured liabilities in the form of a loan, $1-K$ from a risk-neutral perfectly competitive market with opportunity cost of funds equal to $1+r_{f}$, where $r_{f} \geq 0$ indicates the riskless net return. As we will illustrate below, by focusing on uninsured liabilities we allow market discipline to work most effectively.

We denote by $D$ the break-even repayment promised to the lender on a $1-K$ loan. For modeling purposes we will consider a newly-created bank that operates with an exogenous level of capital. The economic intuition we will produce will allow us to analyze the case of an ongoing bank with a standing portfolio of assets and liabilities where changes in the level of capital can be thought of as the result of the previous period's random cash flows.

The bank can invest in risky assets indexed by $i=1, \ldots, n$, and in a riskless asset. The riskless asset returns $1+r_{f}$. Unobservable effort $e>0$ may be devoted to monitor investments in any risky asset. Monitoring effort may be devoted to more than one risky asset, but as we will show later, if the bank monitors it will monitor only one risky asset. Only the bank has the skills to monitor risky investments, which justifies financial intermediation. 
We consider a moral hazard problem similar to Holmström and Tirole (1997). With monitoring effort $e$ the probability of success of investment in asset class $i$ is $p_{i}$, as opposed to $p_{i}-\Delta_{i}>0$ absent monitoring effort, with $\Delta_{i}>0$. The return $X$ per unit of investment in asset class $i$ is $X_{i}>0$ in case of success, and 0 in case of failure for all asset classes. We make no assumption about the joint distribution of asset returns. The key feature of this set up is that some asset classes entail higher agency problems so that the cash flows that can be paid to outsiders are lower. Since, for reasons that will be clear later, we do not want that the market can condition funding on the class of risky assets the bank chooses, we assume that the returns $X_{i}$ are observable but not verifiable by the market. Banks can also invest in the risk-free asset that requires no monitoring. Universal risk neutrality allows us to abstract from loan portfolio diversification to concentrate on the basic problem of moral hazard in asset choices. We make a number of assumptions about parameters values.

Assumption 1 (positive expected value): only when monitoring takes place the expected return of the investments in a risky asset net of monitoring cost exceeds the return from the risk-free asset; i.e.

$$
p_{i} X_{i}-e>1+r_{f}>\left(p_{i}-\Delta_{i}\right) X_{i}, \forall i
$$

The next two assumptions capture the notion of a risk-return frontier of the risky asset classes.

Assumption 2 (assets ranking by expected value): risky assets with higher index have a higher expected value with and without monitoring; i.e.

$$
\begin{aligned}
& \text { a) } p_{1} X_{1}-e \leq p_{2} X_{2}-e \leq, \ldots, \leq p_{n} X_{n}-e \\
& \text { b) }\left(p_{1}-\Delta_{1}\right) X_{1} \leq\left(p_{2}-\Delta_{2}\right) X_{2} \leq, \ldots, \leq\left(p_{n}-\Delta_{n}\right) X_{n} .
\end{aligned}
$$

Furthermore we assume: 
Assumption 3 (assets ranking by risk): asset classes with higher expected value have a lower probability of success, with and without monitoring; i.e.

$$
\begin{aligned}
& \text { a) } p_{n}<, \ldots,<p_{2}<p_{1}, \\
& \text { b) } p_{n}-\Delta_{n}<, \ldots,<p_{2}-\Delta_{2}<p_{1}-\Delta_{1} .
\end{aligned}
$$

It is important to specify the information and contracting structure of the financing and investment game. First, the composition of bank portfolio (i.e. both the asset class $i$ and the proportion $\alpha$ of risky assets) is observable but not verifiable, hence not contractible. Thus a regulatory authority is needed to set and enforce restrictions on both. Notice that simply assuming that the regulator has superior information with respect to the market (Peek et al. 1999, Berger et al. 2000) would not restore efficiency in this context as the market lacks the power to grant and revoke licences and impose penalties. Second, monitoring effort is unobservable to either the market or the regulator. Finally, the market observes the equilibrium asset choice and infers bank's effort decision, and prices debt accordingly.

The timing of the model is as follows: at $\mathrm{t}=0$ the level of bank capital is exogenously determined and made public; at $\mathrm{t}=1$ the regulator determines both the maximum fraction, and the class of risky assets allowed for a certain level of capital; at $\mathrm{t}=2$ the market sets promised repayments, and provides funds; at $\mathrm{t}=3$ the bank decides both the class of risky assets it invests in, and the monitoring effort; at $\mathrm{t}=4$ returns are realized, and repayment made.

\section{Unregulated banking}

To begin with, we investigate under which conditions a bank can operate without any regulatory restriction. In our model, this will be possible provided the bank holds sufficient capital so that it has incentives to monitor its investments in risky assets. As we will, only in this case the market 
provides funds to the bank. For the sake of exposition it is convenient to assume that the bank chooses to invest in, and monitor, only one asset - later in this section we will prove that this is indeed the optimal bank's choice.

In the absence of regulation bank's investment depends only upon the level of capital. Recall that the market observes the equilibrium asset choice and infers the bank's effort decision, and prices debt accordingly. Thus for each risky asset class $i$ the break-even condition for the perfectly competitive credit market is

$$
(1-K)\left(1+r_{f}\right)=p_{i} D_{i}+\left(1-p_{i}\right)\left(1+r_{f}\right)(1-\alpha)
$$

where $D_{i}$ is the repayment promised to the lender in case of success when the fraction of risky investment in asset class $i$ is $\alpha$ and the rest is invested in the risk-free asset. Observe that from $(3.1)$

$$
D_{i}=\frac{(1-K)\left(1+r_{f}\right)-\left(1-p_{i}\right)\left(1+r_{f}\right)(1-\alpha)}{p_{i}}
$$

and, that debt is risk-sensitive, as $\frac{\partial D_{i}}{\partial \alpha}>0$.

For the moment let us hold fixed the risky asset class $i$ to invest in. Using (3.2) the bank's objective function with monitoring $p_{i}\left(\alpha X_{i}+(1-\alpha)\left(1+r_{f}\right)-D_{i}\right)-e \quad$ becomes $p_{i} \alpha X_{i}+\left(1+r_{f}\right)((1-\alpha)-(1-K))-e$ which is increasing in $\alpha$ since, by assumption $1, p_{i} X_{i}>1+r_{f}$. Hence, absent regulation the bank will never invest in the safe asset, i.e. the bank would choose $\alpha=1$ for all $i$.

Let us now return to the issue of how many risky assets the bank will monitor, if it monitors, and establish the following result.

Lemma 1. The bank will devote effort to monitor only one risky asset, the one with the highest expected value. 
Proof. See the appendix.

The intuition is straightforward. Disregarding monitoring costs, given risk neutrality the objective function of the bank is convex, and a corner solution is optimal: the bank invests only in the asset with the highest expected value. Furthermore, monitoring costs increase if the bank invests in more assets.

Next, we turn to the exploration of the banks' incentives to monitor their risky investments. Notice that, regardless of the level of capital, unless the bank has incentives to monitor the risky investments, it will not be funded. Indeed without monitoring the sum of the expected returns of the bank and of the market is less than the opportunity cost of the funds by assumption 1; i.e.

$$
\left(p_{i}-\Delta_{i}\right)\left(X_{i}-D_{i}\right)+\left(p_{i}-\Delta_{i}\right) D_{i}<1+r_{f}, \forall i
$$

Absent regulation the bank's incentive to monitor an investment in asset class $i$ is

$$
p_{i}\left(X_{i}-D_{i}\right)-e \geq\left(p_{i}-\Delta_{i}\right)\left(X_{i}-D_{i}\right)
$$

or, equivalently, $X_{i}-\frac{e}{\Delta_{i}} \geq D_{i}$. Having established that absent regulation the bank never invests in the safe asset, and since for Lemma 1 the bank monitors only one risk asset, we can now derive the monitoring incentive constraint as a function of bank capital. Using the market clearing condition (3.2) for $\alpha=1$, equation (3.4) becomes

$$
K \geq K_{i} \equiv \frac{\frac{p_{i} e}{\Delta_{i}}-\left(p_{i} X_{i}-\left(1+r_{f}\right)\right)}{1+r_{f}}
$$

where $K_{i}$ denotes the minimum level of capital that a bank must own to satisfy the incentive to monitor asset class $i$. Equation (3.5) thus imposes a minimum level of capital as a necessary condition for outside funding in asset $i$. Notice that Lemma 1 implies that, a fortiori, the bank could 
not satisfy the monitoring incentive constraint combining any two risky assets. ${ }^{4}$ Equation (3.5) can be expressed as

$$
p_{i}\left(X_{i}-\frac{e}{\Delta_{i}}\right) \geq(1-K)\left(1+r_{f}\right)
$$

which has the usual interpretation that the expected cash flow payable to outsiders $p_{i}\left(X_{i}-\frac{e}{\Delta_{i}}\right)$, should not be smaller than the opportunity cost of outside funds (Tirole 2005). From (3.6) since, $K<1$ it follows that $p_{i}\left(X_{i}-\frac{e}{\Delta_{i}}\right)>0$ for all $i$.

We now turn to the question whether unregulated market finance may arise. For the market not to collapse, a necessary condition is that in equilibrium there is no shirking. Lemma 1 tells us that, if there is no shirking, then investment and monitoring will occur in asset $n$. Consequently we have to determine whether the bank has any incentive to deviate from monitoring asset $n$, and shirk in the risky asset that gives the highest expected payoff when the promised repayment is $D_{n}$. From part b) of assumptions 2 and 3 it follows that the best alternative to monitor asset $n$ is to shirk in asset $n$. Therefore necessary condition for unregulated market finance is that equation (3.4) is satisfied for asset $n$, i.e.

$$
p_{n}\left(X_{n}-D_{n}\right)-e \geq\left(p_{n}-\Delta_{n}\right)\left(X_{n}-D_{n}\right) \text {. }
$$

Recalling that from (3.2) $p_{n} D_{n}=(1-K)\left(1+r_{f}\right)$ for $\alpha=1$, and observing that $\frac{\partial D_{n}}{\partial K}<0$, then (3.7) is violated for high $e$ and low $K$. Recalling furthermore that $K_{n}$ is the value of $K$ such that equation (3.7) is satisfied with equality, then, if a bank has a level of capital $K<K_{n}$ the market collapses and we cannot have unregulated market finance.

\footnotetext{
${ }^{4}$ Notice that if the bank has enough capital to monitor more than one risky asset and if after a given size returns in each risky asset go to zero then the bank will choose a portfolio composed of several risky assets starting with the ones with the highest present value, hence generalizing Lemma 1. Since the qualitative results of the model would not change, in what follows we will not formalize this more general model specification. Focusing on a bank that invests and monitors only one asset is thus a justifiable abstraction in the interest of simplicity.
} 


\section{Regulation with moral hazard}

Having identified the necessary condition for unregulated market finance we now investigate how the regulator can improve welfare if the market collapses. Recall that we have assumed that portfolio composition is not contractible. Hence the authority, e.g. by a regulator, is called upon to set and enforce portfolio restrictions. Indeed one dimension of banking regulation is the power to inspect banks and to grant and revoke licences on the basis of this information (see e.g. Bhattacharya et al. 2002), a power that the market does not have. In what follows we successively consider two regulatory tools: capital regulation and restrictions on the portfolio of risky assets, i.e. the prohibition of investments in certain assets to increase the expected value of the banking industry. Our objective here is to examine whether these two instruments could be considered as substitutes. The basic argument for considering these two regulatory measures as possible substitutes is that when we impose capital regulation we force the bank to restructure its portfolio so as to invest in less risky projects, which is precisely what we obtain if we simply prohibit the projects with higher risks. As we will see, nevertheless, the analysis of moral hazard will lead us to identify the differences between these two regulatory instruments.

Although another important dimension of modern banking regulation is deposit insurance here we allow only for uninsured liabilities. Our results would not change if we were to consider insured liabilities. If liabilities are insured by a fairly-priced deposit insurance scheme their cost is identical to that imposed by a risk-neutral perfectly competitive lending market. Under a flat deposit insurance scheme instead, rents on deposits would be maximized by choosing the riskiest asset, as shown in Lemma 1 where the interest rate charged to the bank by the market does not depend on the chosen project.

The analysis of capital requirements is here justified by the results obtained in the previous section. As noted there, a minimum capital is required, so it is natural to set these limits as capital requirements: at least a capital $K_{n}$ is required in order to invest in asset $n$, a capital $K_{n-1}$ in order to invest in assets $n-1$, and so on. If so, for a portfolio of assets represented by an nx1 vector $\underline{\lambda}$ whose 
components $\lambda_{i}, 0 \leq \lambda_{i} \leq 1$, are the proportions of investment in risky assets $i$, with $\sum_{i}^{n} \lambda_{i}=1$, capital regulation imposes that $\sum_{i}^{n} \lambda_{i} K_{i} \leq K$. For the same convexity reasons that make Lemma 1 hold, under a capital constraint the optimal portfolio will be obtained at a corner solution. This implies that it will combine, at most, two risky assets. We will focus on the case of a sufficiently high effort cost $e$, so that effort duplication will never be optimal. This will allow us to restrict our analysis to the comparison of portfolios composed of one risky asset and the safe asset.

We will show that in some range of values capital regulation will not succeed in holding back non-monitored assets. In particular we establish the following result:

Proposition 1. Capital regulation does not prevent a bank from investing in asset $n$ without monitoring it rather than investing and monitoring asset $n-1$.

Proof. See the appendix.

Consequently, capital requirement regulation may fail to prevent the choice of the asset with the highest risk and substitute it by the next best asset. Still, this needs not be a problem if capital regulation provides the right incentives to invest a fraction $\alpha$ of the portfolio in the monitored asset $n$ and the rest in the safe asset.

Given $\alpha$, for each asset class $i$ the bank's incentive to monitor an investment in the risky asset class $i$ is

$$
p_{i}\left(\alpha X_{i}+(1-\alpha)\left(1+r_{f}\right)-D_{i}\right)-e \geq\left(p_{i}-\Delta_{i}\right)\left(\alpha X_{i}+(1-\alpha)\left(1+r_{f}\right)-D_{i}\right)
$$

which becomes

$$
\alpha X_{i}+(1-\alpha)\left(1+r_{f}\right) \geq \frac{e}{\Delta_{i}}+D_{i}
$$


Since for Lemma 1 the bank will monitor only one risky asset we can now derive the capital constraint when the bank may face restrictions on the fraction $\alpha$ of a risky asset $i$. Using the break even condition (3.2), equation (4.2) becomes

$$
\alpha X_{i}+(1-\alpha)\left(1+r_{f}\right) \geq \frac{e_{i}}{\Delta_{i}}+\frac{(1-K)\left(1+r_{f}\right)-\left(1-p_{i}\right)\left(1+r_{f}\right)(1-\alpha)}{p_{i}}
$$

or

$$
K \geq \frac{\frac{p_{i} e_{i}}{\Delta_{i}}-\alpha\left(p_{i} X_{i}-\left(1+r_{f}\right)\right)}{1+r_{f}} .
$$

The RHS of (4.4) indicates the minimum level of capital, for each value $\alpha \geq 0$, that a bank must own in order to have the incentive to monitor an investment in asset class $i$. Part b) of assumptions 2 and 3 guarantees that if (4.4) is satisfied the bank has no incentive to shirk in an asset with an index $<i$.

To focus on the interesting case, where it is not possible to finance a project exclusively through external debt, we make the following assumption.

Assumption 4 (positive capital): for every asset $i$, the expected cash flow that can be paid to outsiders $p_{i}\left(X_{i}-\frac{e}{\Delta_{i}}\right)$ is smaller than the opportunity cost of funds, $\left(1+r_{f}\right)$; i.e. $1+r_{f}>p_{i}\left(X_{i}-\frac{e}{\Delta_{i}}\right)$, for all $i$

This leads us to the following result.

Proposition 2. For any risky assets $i=1, \ldots n-1$ if a bank has a level of capital such that $K<K_{n}$ (i.e. unregulated market finance is impossible) then either the parameters are such that equation (4.4) is satisfied for $\alpha=1$, that is there are no restrictions on the fraction of assets that can be devoted to 
risky investments, or there is no $\alpha \geq 0$ that can satisfy it. In the latter case, the only way to guarantee that the market funds the bank is for the regulator to $\operatorname{set} \alpha=0$, that is to prohibit any investment in asset class $i$.

The proof is obvious given assumption 1 that guarantees that the RHS of (4.4) is a decreasing function of $\alpha$. The intuition for Proposition 2 is that by forcing the bank to invest a large fraction in the safe asset the regulator lowers the bank's expected profit and thus its incentive to monitor the risky asset. Since the lower the level of capital the higher is the promised debt repayment, then there are parameter constellations such that it is impossible to provide incentives to monitor the investment in risky asset $i$ given the amount of capital. In such cases, capital regulation is powerless and prohibition of any investment in that asset class is the only way to have the bank funded. ${ }^{5}$

It is well known (Tirole 2005) that in this type of models there are two sources of agency problems: the likelihood ratio $\frac{\Delta_{i}}{p_{i}}$ and the effort levele. They yield a maximum level of expected cash flow from investment in risky asset $i$ that can be paid to outsiders equal to $p_{i}\left(X_{i}-\frac{e}{\Delta_{i}}\right)$. Our paper makes the point that agency problems may be more severe in certain asset classes than in other so that it may be more costly to provide incentives to monitor investments in those asset classes. More innovative investments, for example in derivatives, bridge loans for M\&A, proprietary equity trading, hedge fund financing, may be more opaque, and therefore leave more scope for managerial discretion, than more traditional credit operations, thus requiring more costly incentives. To reflect this idea in a straightforward way, we make the following assumption that links the expected value from investing in a risky asset to the cash flow that can be paid to outsiders once we account for the cost of managerial incentives.

\footnotetext{
${ }^{5}$ Proposition 2 is related to the credit rationing results of Aghion and Bolton (1997) and Piketty (1997) in growth models with moral hazard where individuals have heterogeneous wealth endowments.
} 
Assumption 5 (negative correlation between expected values and expected pledgeable cash flow): asset classes with higher expected value have lower expected pledgeable cash flow; i.e.

$$
p_{1}\left(X_{1}-\frac{e}{\Delta_{1}}\right)>p_{2}\left(X_{2}-\frac{e}{\Delta_{2}}\right)>, \ldots,>p_{n}\left(X_{n}-\frac{e}{\Delta_{n}}\right)
$$

Thus asset class 1 leaves more expected cash flow payable to outsiders than asset class 2 , and so on. Figure 1 illustrates the decreasing relationship between expected pay-offs and expected pledgeable cash-flows that is implied by the combination of assumptions 2 and 5.

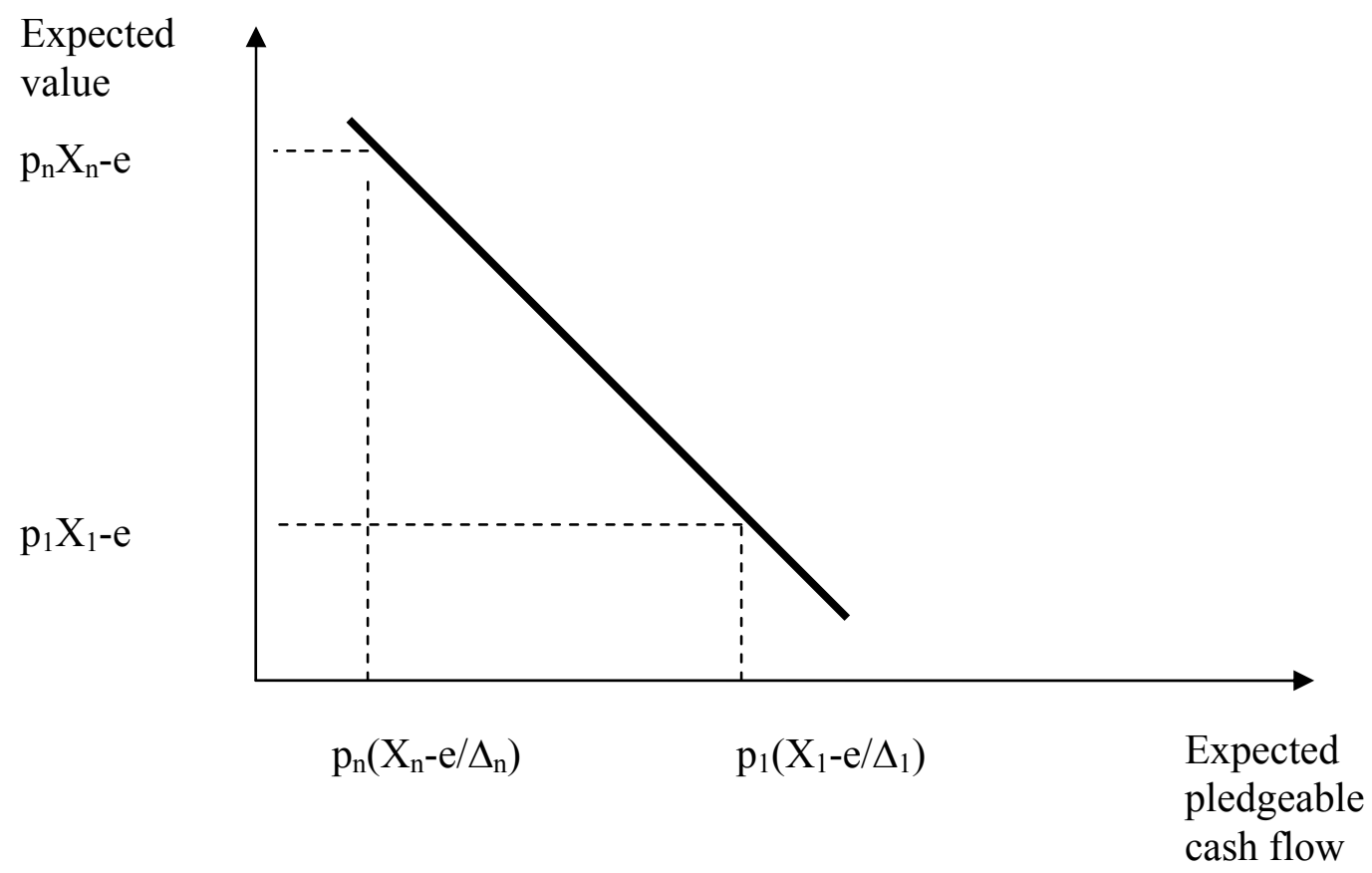

Figure 1: Expected values and expected pledgeable cash flows: an example.

Assumption 5 deserves some comments. First, its motivation is to focus on a simplified case where a major tension exists between net present value maximization and moral hazard. Alternative assumptions, while leading to the same qualitative results regarding the benefits of regulatory restrictions to complement capital ratios, would make the analysis more cumbersome and would introduce additional complexities making the intuition of our result less clear. This tension between net present value and moral hazard is required in order to point out why prohibiting some activity could be efficient. Second, more generally we stress that the value to outsiders of opaque banks 
assets is linked to the cost of providing proper incentives to the bankers, and not necessarily to the their net present value. Finally, notice that the ranking is a characteristic of the assets in the whole economy and not of the asset portfolio of a particular bank.

Before introducing our main result on optimal bank regulation we have to establish the bank optimal asset choice assuming the bank always monitors. This will be the one with the highest expected value among those that satisfy the monitoring constraint.

Lemma 2. Assume there is a subset of asset classes $\{1, \ldots, j\}$ in which monitoring takes place, i.e. equation (4.4) is satisfied for $\alpha=1$. Then, the bank prefers $j$ to any project $k$ such that $k<j$.

Proof. See the appendix.

Recall that $K_{i}$ in (3.5) defines the monitoring threshold for investment in asset class $i$ and that the negative correlation assumption implies an ordering of the monitoring threshold such that $K_{l}<, \ldots,<K_{j}<, \ldots,<K_{n}$ and assumption 4 on minimum capital implies $K_{l}>0$. We are now in a position to establish our main result about optimal bank capital regulation.

Proposition 3. The optimal capital regulation is characterized as follows.

1) For banks with a level of capital $K$ such that $K \geq K_{n}$ it is optimal to set no restrictions either on the type of risky investment that the bank is allowed to undertake or on the percentage of investment in risky asset classes, that is it is optimal to set $\alpha=1$.

2) For banks with a level of capital $K$ such that $K_{j+1}>K \geq K_{j}$ for $j=1, \ldots, n-1$ it is optimal to prohibit investments in all risky asset classes with index $>j$ and to allow the bank to invest $\operatorname{all}(\alpha=1)$ in risky asset classes with index $\leq j$ (see figure 2). 
3) For banks with a level of capital $K$ such that $0<K<K_{1}$ it is optimal to prohibit investments in all risky asset classes and to allow investment in the risk-free asset only, that is it is optimal to set $\alpha=0$.

Proof. See the appendix.

Allowed asset classes

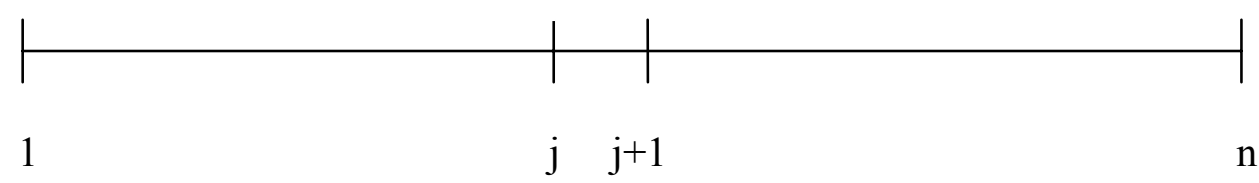

Figure 2. Optimal regulation for banks with intermediate capital, $K_{j+1}>K \geq K_{j}, \mathrm{j}=1, \ldots, \mathrm{n}-1$

The first part of Proposition 3 states that if a bank has a sufficiently high level of capital such that the incentive to monitor is preserved even for the investments in the most opaque asset class, then regulation should not restrict its choices as the market will fund it anyway. The second part of Proposition 3 says that for banks with an intermediate level of capital the only way to guarantee that the bank has incentives to monitor, and thus it is funded by the market, is to prohibit investments in the most opaque asset classes even if those investments have the highest expected value. The third part of Proposition 3 posits that for banks with low level of capital the only way to guarantee that the market funds the bank is to prohibit investments in risky assets altogether.

Several comments are in order. First, this result captures in a stylized way one of the main messages of the PCA regulation, namely that the lower the bank capital ratio the fewer are the types of investments that the bank is allowed to undertake. Notice that these are both qualitative and quantitative restrictions on bank's actions that achieve results (bank funding) that could not have 
been achieved with traditional capital regulation alone as shown in Proposition $2 .^{6}$ Second, since the prohibition of certain investments allows a reduction of the level of capital to satisfy the monitoring constraint, then this rule effectively economizes on capital for a given bank size or, alternatively, it allows increasing bank size given capital. In the following section we will tackle these issues. Third, as mentioned, the role of the negative correlation assumption (assumption 5) in Proposition 3 is merely to simplify matters and provide a clear-cut analysis of the case in point, where a major tension exists between net present value maximization and moral hazard. If we completely reverse the assumption, and assume a positive correlation, then such a tension ceases to exist and capital regulation is sufficient to cope with both, provided risk weights are conveniently chosen. So in a positive correlation case the very essence of the problem we are focusing on disappears, and there is no rationale for a PCA policy. The general case can only be understood through the intuition built on our model. As we will have locally increasing or decreasing relationships between expected net present values and expected pledgeable cash flows, this will imply that, as capital decreases, for some projects capital requirement will be sufficient to solve the moral hazard issues, but for others a prohibition will be necessary to allow the bank to successfully tap the market for funds.

As noted, one of the rationales of the PCA regulation was to mandate some interventions for undercapitalized banks rather than relying on regulatory discretion only. Although in this paper we do not address the issue of the costs and benefits of having rules vs regulatory discretion, the rule we have derived in Proposition 3 can be interpreted as the optimal contract between the regulator and the bank. The bank would find it optimal to subscribe to that contract because having its hands tied, i.e. being in the impossibility to invest in some moral hazard-sensitive projects would allow it to have access to finance. In this model, absent unforeseen contingencies that might make discretion preferable with respect to rigid rules, commitment to that contract would dominate an ad

\footnotetext{
${ }^{6}$ The result that qualitative restrictions on the set of allowed investments may be optimal is similar to the prohibition of certain difficult-to-observe tasks in the multi-task principal-agent model of Holmström and Milgrom (1991).
} 
hoc method of bank crisis resolution. Indeed discretion might lead to forbearance, that if anticipated by the market would result in less funding for bank investment, or otherwise may shift the cost of crisis resolution to lender of last resort facilities.

It is important to interpret our results in the context of the literature on capital regulation. First, notice that in this model we do not exclude a priori traditional capital regulation. The fact that the optimal value of $\alpha$ is 1 is the result of the need to satisfy an incentive constraint which could not be done with quantitative restrictions on capital alone. Second, observe that in this model the traditional role of capital regulation - maintaining stability and solving depositors' collective action problems - is not operational because liability holders subject financial intermediaries to perfect market discipline as loans are fairly priced. However, liability holders are not capable to enforcing contingent contracts as to the asset choices. Hence, PCA regulation with qualitative asset prohibitions is needed to integrate quantitative capital regulation when the opacity of bank assets is an issue.

\section{Variable bank size}

Up to now we have considered a fixed capital and fixed size framework, so that capital regulation would imply that banks had to invest a fraction of their assets in the riskless asset. In fact, the bank could comply with capital regulation by contracting the scale of their operations. But scale would be observable and contractible and therefore the bank might be subject to market discipline. Consequently, considering the possibility of a variable bank size is quite relevant for our analysis, as it allows examining the possible trade-offs between scale and scope of banks.

For this reason we now turn to the case of variable asset size. The bank has to decide the scale of its overall activities as well as the composition of the portfolio of risky assets. Assume that

asset size $I$ is such that $I \in[0, \bar{I}], \bar{I}$ being the maximum capacity. This intermediate assumption between fixed and completely variable asset size captures the idea that after a certain scale returns 
are sharply decreasing. Asset size $I$ is funded by capital $K$ and by fairly priced loans, $I-K$. Production has constant returns to scale: with success the return is $I X_{i}$ for all $i$, with failure 0 . Effort is assumed proportional to asset size so that $e I$ is the effort to monitor any risky asset of size $I$. Probability of success and failure with and without monitoring are as in the fixed-size case.

Since bank size is determined together with funds request and thus, as in the previous sections, it is given at the stage of asset choice, then Lemma 1 applies, i.e. the bank will monitor only one risky asset, if it monitors at all. The timing and the remaining assumptions are as in the fixed-size case.

The break-even constraint for the risk-neutral competitive lender becomes

$$
(I-K)\left(1+r_{f}\right)=p_{i} D_{i}+\left(1-p_{i}\right)\left(1+r_{f}\right)(1-\alpha) I
$$

and the bank objective function is

$$
p_{i}\left(\alpha X_{i} I+(1-\alpha)\left(1+r_{f}\right) I-D_{i}\right)-e I
$$

Using (4.6) expression (4.7) becomes

$$
I\left(\alpha p_{i} X_{i}+(1-\alpha)\left(1+r_{f}\right)\right)-e I-\left(1+r_{f}\right)(I-K)
$$

which is increasing in $\alpha$ since $p_{i} X_{i}>1+r_{f}$. Thus again given the amount borrowed $I-K$ the bank will not invest in the safe asset unless forced to do so. The monitoring incentive constraint becomes $^{7}$

$$
K \geq I\left[\frac{\frac{p_{i} e}{\Delta_{i}}-\alpha\left(p_{i} X_{i}-\left(1+r_{f}\right)\right)}{1+r_{f}}\right]=\frac{1}{m_{i}} I
$$

where the "multiplier" $m_{i}$ is

$$
m_{i} \equiv \frac{1+r_{f}}{\frac{p_{i} e}{\Delta_{i}}-\alpha\left(p_{i} X_{i}-\left(1+r_{f}\right)\right)}
$$

\footnotetext{
${ }^{7}$ The derivation of the expression (4.9) follows the same logic of the equivalent constraint in section 4 . For a very similar expression of the borrowing capacity see Tirole (2005) p.127.
} 
Notice that once bank size is determined, banker's decision follows the same logic of the fixed-asset size. For all asset classes $i, \frac{\partial m_{i}}{\partial \alpha}>0$, because of assumption 1. Therefore, given asset size and asset class, either the monitoring constraint (4.9) is satisfied for $\alpha=1$ or there is no value $\alpha>0$ that can satisfy it, a result similar to Proposition 2. Thus considering the value of (4.10) when $\alpha=1$, the investment multiplier becomes:

$$
m_{i} \equiv \frac{\left(1+r_{f}\right)}{\left(1+r_{f}\right)-p_{i}\left(X_{i}-\frac{e}{\Delta_{i}}\right)}>1
$$

because of the maintained assumption 4 that $1+r_{f}>p_{i}\left(X_{i}-\frac{e}{\Delta_{i}}\right)$, for all $i$.

Under the negative correlation assumption (assumption 5) it follows that $m_{1}>, \ldots,>m_{n}$ which implies that the multiplier can be increased by prohibiting investments in the most opaque asset classes. Define the variable $I_{i} \equiv K m_{i}$, as the maximum size of asset $i$ given the level of capital $K$, compatible with monitoring incentives and thus market funding. Absent regulation, unless the bank has enough capital such that $I_{n} \geq \bar{I}$, then in order to get funded it will lower its size to the point that the monitoring constraint is satisfied. Thus for the banks with capital such that $I_{n}<\bar{I}$ a regulation prohibiting investment in the most opaque assets allows to increase size. This leads us to the following result.

Proposition 4: 1) If the level of capital is such that $I_{n} \geq \bar{I}$ then placing restrictions on bank asset choice would not increase funding; 2) If instead the level of capital is such that $I_{n}<\bar{I}$ a regulation prohibiting investment in the most opaque asset classes can increase the multiplier and thus funding. 
The proof follows in a straightforward way from the assumption that $I \in[0, \bar{I}]$, and the definition of $I_{i}$. In case 1 , the bank is sufficiently capitalized so that even the investment in the most opaque asset $n$ satisfies the monitoring constraint for the relevant range of investment opportunities; no restriction on asset choices would improve welfare. The zero marginal returns after reaching the maximum scale induces the bank to choose a size for which it has incentives to monitor.

In case 2 , despite the market providing some funding, size is limited by the scarcity of capital and by the opacity of bank assets, so that, absent regulation, only partial funding to exploit investment opportunities can be obtained. Case 2 shows that one can satisfy the monitoring constraint (4.9) either by increasing the multiplier (i.e. prohibiting investment in certain asset classes) or by lowering bank size, or both. Thus the regulator faces a trade-off between allowing investments in many asset classes (low multiplier) and allowing banks to pursue large levels of overall investment. For an illustration see figure 3.

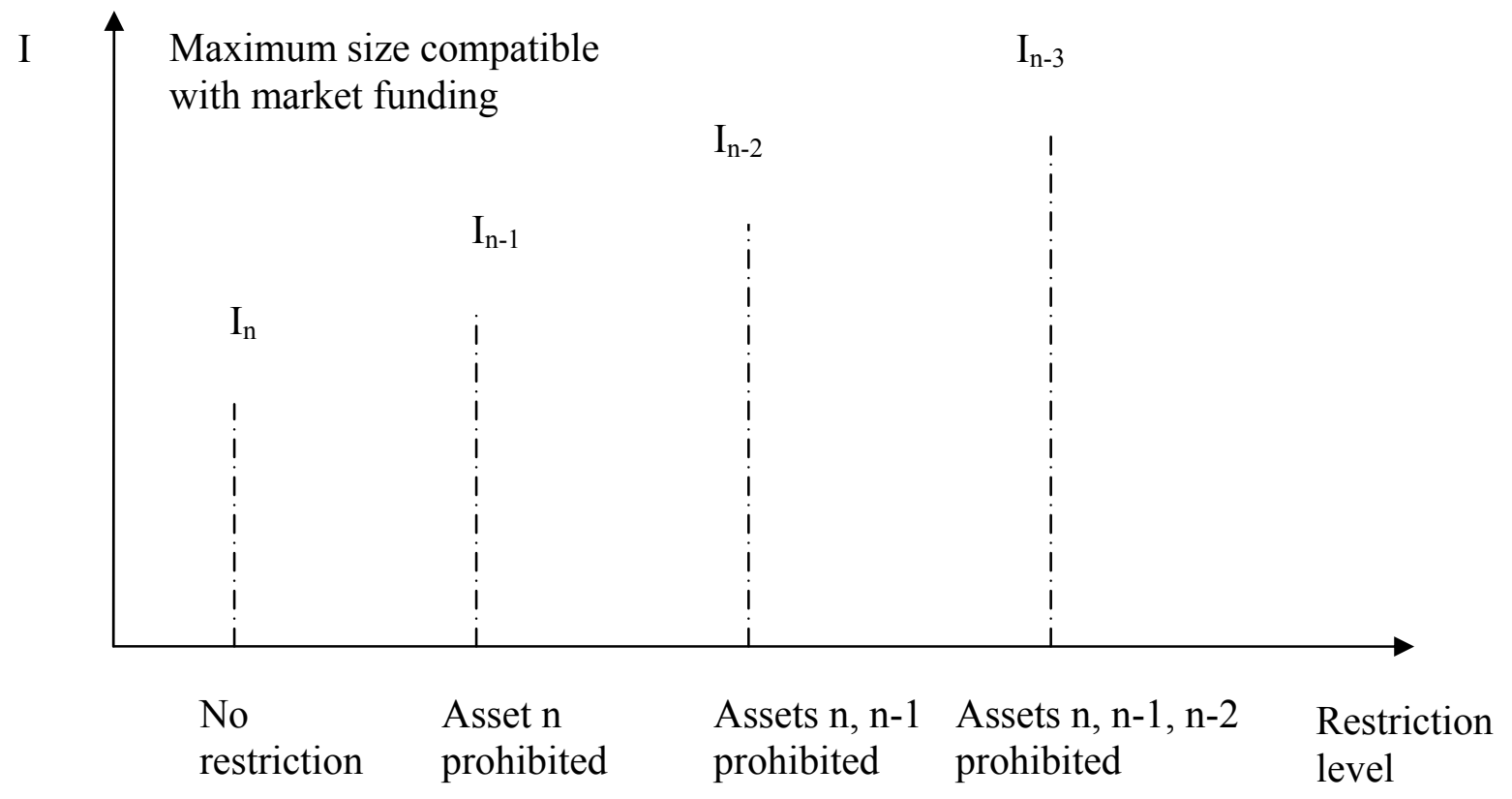

Figure 3: Restrictions and size for banks with scarce capital; $I_{n}<\bar{I}$ 
The main implication of case 2 is that since the welfare function is the net aggregate expected present value of banking investment, the regulator has to consider both the expected return and the size of the investment. Size depends on the moral hazard dimension via the multiplier $m_{i}$. Thus regulation affecting the multiplier $m_{i}$ effectively determines the size of the overall bank investments. Under our assumption of negative correlation the higher the index of the asset class the lower the maximum size of the investment for a given capital compatible with monitoring incentives. Thus as we move from asset 1 to $n$, we go from a combination of high expected returnlow size to a combination of low expected return-high size. The optimal choice depends on the characteristics of the risky assets and in particular on the relationship between expected value and expected pledgeable cash flow. The main difference with respect to the fixed-size result of Proposition 3 is that banks with little capital can still invest in opaque assets albeit at a small scale.

Furthermore, the notion that the incentive constraint can be satisfied also by allowing the bank to invest in opaque assets thus effectively lowering the overall bank size can be interpreted as downsizing a bank to force it to satisfy a certain capital requirement. Finally, the incentive constraint (4.9) can also be seen as a way to minimize the amount of capital needed to satisfy the monitoring constraint to invest in risky assets of given size. Hence our framework can be applied to study the issue of recapitalization of undercapitalized banks with a given portfolio of loans.

\section{Conclusion}

We have developed a simple framework to study investment choices under moral hazard that can be applied to a variety of corporate finance decisions. What makes it particularly suitable for the analysis of bank capital regulation is the regulator's advantage, stemming from its supervisory and licensing role, in gathering information about bank portfolios and enforcing portfolio restrictions.

Our model shows that the logic behind PCA regulation is well rooted in the microeconomic analysis of banks' incentives. However, our paper has not attempted to provide any analysis for one of the other rationales behind the adoption of PCA in the US, namely the desire to avoid 
forbearance by tightening the regulator's hands and requiring some mandatory actions as a function of capital ratios. In other countries, in particular in the European Monetary Union, bank capital regulation at the national level often follows both the traditional quantitative capital regulation based on risk-weighted capital ratios, and a mix of moral suasion and ad hoc resolution of bank crises. A policy implication of our paper is that a piece of regulation similar to PCA should also be adopted outside the US, especially in countries where a discretionary approach to bank crisis resolution may lead to regulatory capture by the industry. This is particularly true in countries with weak institutional environments where, as Bart. et al. (2006) argue, giving strong discretionary powers to bank supervisors may actually make matters worse. 


\section{Appendix}

\section{Proof of Lemma 1.}

Using a convexity argument, we first show that the bank chooses one risky asset, and then we prove that the selected asset is the one with the highest net present value. Recall that at $\mathrm{t}=2$ the market sets a repayment $D$ as a function of the capital and the equilibrium behavior of the banker. Let $\underline{\lambda}$ be a $\mathrm{nx} 1$ vector whose components $\lambda_{i}, 0 \leq \lambda_{i} \leq 1$, are the proportions of investment in risky assets $i$, with $\sum_{i}^{n} \lambda_{i}=1$. Denote with $\underline{\lambda}^{*}$ the equilibrium vector of proportions chosen by the bank. We introduce the following definition: project $j$ is said to belong to the set $A$ if its realized return is $X_{j}$; project $j$ is said to belong to the set $\bar{A}$ if its realized return is 0 , where $\bar{A}$ is the complement set of $A$. Let us denote with $Z \equiv \wp(A)$ the set of all subsets of $A$ (including the empty set). The expected value of bank profits gross of monitoring cost can be expressed as

$$
\Phi(\underline{\lambda}) \equiv \sum_{S \in Z}\left[p(S)\left(\sum_{j \in S} \lambda_{j} X_{j}-D ; 0\right)\right] .
$$

where $p(S)$ indicates the probability that the projects in set $S$ are successful .

At $\mathrm{t}=3$ the bank will choose $\underline{\lambda}$ to maximize

$$
\Phi(\underline{\lambda})-e \sum_{j}^{n} 1\left(\lambda_{j}>0\right)
$$

where $1\left(\lambda_{j}>0\right)$ is a vector whose $j$-th component takes value 1 when $\lambda_{j}>0$, and 0 otherwise. Notice that $D$ is a function of the equilibrium vector $\underline{\lambda}^{*}$ and not of $\lambda_{j}$. We show now that $\Phi(\underline{\lambda})$ is convex, that is, that for every vector $\underline{\lambda}^{1}$ and $\underline{\lambda}^{2}$ it must be true that

$$
\Phi\left(\alpha \underline{\lambda}^{1}+(1-\alpha) \underline{\lambda}^{2}\right) \leq \alpha \Phi\left(\underline{\lambda}^{1}\right)+(1-\alpha) \Phi\left(\underline{\lambda}^{2}\right) \forall \alpha \in[0,1] .
$$

So it must be the case that 


$$
\begin{aligned}
& \sum_{S \in Z}\left[p(S)\left(\sum_{j \in S}\left(\alpha \lambda_{j}^{1}+(1-\alpha) \lambda_{j}^{2}\right) X_{j}-D ; 0\right)\right] \leq \\
& \sum_{S \in Z}\left[p(S)\left(\alpha \max \left(\sum_{j \in S} \lambda_{j}^{1} X_{j}-D ; 0\right)+(1-\alpha) \max \left(\sum_{j \in S} \lambda_{j}^{2} X_{j}-D ; 0\right)\right)\right] .
\end{aligned}
$$

Two cases are possible: if $\sum_{j \in S}\left(\alpha \lambda_{j}^{1}+(1-\alpha) \lambda_{j}^{2}\right) X_{j} \leq D$ then the LHS of (6.4) is equal to 0 , and (6.3) is satisfied. If $\sum_{j \in S}\left(\alpha \lambda_{j}^{1}+(1-\alpha) \lambda_{j}^{2}\right) X_{j}>D$ then

$$
\begin{aligned}
& \sum_{S \in Z}\left[p(S)\left(\sum_{j \in S}\left(\alpha \lambda_{j}^{1}+(1-\alpha) \lambda_{j}^{2}\right) X_{j}-D ; 0\right)\right]= \\
& \sum_{S \in Z}\left[p(S)\left(\sum_{j \in S}\left(\alpha \lambda_{j}^{1}+(1-\alpha) \lambda_{j}^{2}\right) X_{j}-D\right)\right]= \\
& \sum_{S \in Z}\left[p(S)\left(\alpha \sum_{j \in S} \lambda_{j}^{1} X_{j}+(1-\alpha) \sum_{j \in S} \lambda_{j}^{2} X_{j}-D\right)\right] \leq \\
& \sum_{S \in Z}\left[p(S)\left(\alpha \max \left(\sum_{j \in S} \lambda_{j}^{1} X_{j}-D ; 0\right)+(1-\alpha) \max \left(\sum_{j \in S} \lambda_{j}^{2} X_{j}-D ; 0\right)\right) .\right.
\end{aligned}
$$

This shows that $\Phi(\underline{\lambda})$ is convex.

It is standard to show that the maximization of the convex function $\Phi(\underline{\lambda})$ over the hyperplane $\sum_{i}^{n} \lambda_{i}=1$ yields a corner solution. From

$$
\begin{aligned}
& \Phi\left(\alpha \underline{\lambda^{1}}+(1-\alpha) \underline{\lambda}^{2}\right) \leq \alpha \Phi\left(\underline{\lambda}^{1}\right)+(1-\alpha) \Phi\left(\underline{\lambda}^{2}\right) \leq \\
& \alpha \max \left\{\Phi\left(\underline{\lambda}^{1}\right), \Phi\left(\underline{\lambda}^{2}\right)\right\}+(1-\alpha) \max \left\{\Phi\left(\underline{\lambda}^{1}\right), \Phi\left(\underline{\lambda}^{2}\right)\right\} \leq \max \left\{\Phi\left(\underline{\lambda}^{1}\right), \Phi\left(\underline{\lambda}^{2}\right)\right\}
\end{aligned}
$$

by quasiconvexity. Recall that we denote with $\underline{\lambda}^{*}$ the vector that maximizes (6.2). Assume that

$$
\underline{\lambda}^{*} \neq(0,0, \ldots, 1, \ldots .0,0) \equiv \delta_{k}
$$

where $\delta_{k}$ is the canonical base where the $k$-th element is 1 , so that $\underline{\lambda}^{*}=\sum_{j=1}^{n} \alpha_{j} \delta_{j}$, and let $J=\{j=\{1,2, \ldots, n\}\}, \alpha_{j}>0$. Because the $\delta_{k}$ are in the feasible set, then by quasiconvexity it follows that 


$$
\Phi\left(\underline{\lambda}^{*}\right) \leq \max _{k \in J} \Phi\left(\delta_{k}\right)
$$

Since $\underline{\lambda}^{*}$ is optimal then

$$
\Phi\left(\underline{\lambda}^{*}\right) \geq \max _{k \in J} \Phi\left(\delta_{k}\right)
$$

So that $\Phi\left(\underline{\lambda}^{*}\right)=\max _{k \in J} \Phi\left(\delta_{k}\right)$.

Since with $\delta_{k}$ the introduction of effort's cost benefits a lower number of risky asset classes monitored with respect to $\underline{\lambda}^{*}$, the optimal choice conditional on monitoring is to invest in only one risky asset. We now show that this will be the $n$-th asset. This is the case since $D$ is independent of $k$. Notice first that $\Phi\left(\delta_{n}\right)=p_{n}\left(X_{n}-D\right)$ for any $D$ such that $p_{j^{*}} D=\left(1+r_{f}\right)(1-K)$ where $j^{*}$ is the asset chosen by the bank. For any $j$ such that $\Phi\left(\delta_{j}\right)=0$ asset $n$ is obviously preferred. For $j$ such that $\Phi\left(\delta_{j}\right)>0$, combining assumption 1 and 3 we have $p_{n} X_{n} \geq p_{j} X_{j}$ and $p_{n} D \leq p_{j} D$. Consequently $\Phi\left(\delta_{n}\right) \geq \Phi\left(\delta_{j}\right), j=1,2, \ldots, n$, with equality only for $j=n$.

Proof of Proposition 1. Consider the bank's choice when it is confronted with a capital requirement $\sum_{i}^{n} \lambda_{i} K_{i} \leq K<K_{n}$ for $K=\lim _{\varepsilon \rightarrow 0} K_{n}-\varepsilon$. We show that the bank prefers to invest in asset $n$ without monitoring than to invest and monitor asset $n-1$. In order to do that, denote by $D_{k}$ the repayment due when asset $k$ is chosen, so that $p_{k} D_{k}=\left(1+r_{f}\right)(1-K)$. Then, because $D_{n}>D_{n-1}$ it follows that $\left(p_{n}-\Delta_{n}\right)\left(X_{n}-D_{n-1}\right)>\left(p_{n}-\Delta_{n}\right)\left(X_{n}-D_{n}\right)$. Next, at the limit $K=K_{n}$, $\left(p_{n}-\Delta_{n}\right)\left(X_{n}-D_{n}\right)=p_{n}\left(X_{n}-D_{n}\right)-e$. But assumption 2 jointly with $p_{k} D_{k}=\left(1+r_{f}\right)(1-K)$ implies $\quad p_{n}\left(X_{n}-D_{n}\right)-e>p_{n-1}\left(X_{n-1}-D_{n-1}\right)-e$. Thus, by transitivity $\left(p_{n}-\Delta_{n}\right)\left(X_{n}-D_{n-1}\right)>p_{n-1}\left(X_{n-1}-D_{n-1}\right)-e$ and the bank prefers to invest in asset $n$ without 
monitoring to monitoring asset $n-1$. By continuity, the inequality will hold true in a neighbourhood of $K_{n},\left(K_{n}-v, K_{n}\right)$ for a sufficiently small $v$.

\section{Proof of Lemma 2.}

Recall that by assumption 2 we have that for $k<j, p_{j} X_{j} \geq p_{k} X_{k}$, and by assumption $3 p_{k}>p_{j}$. Hence

$$
p_{j}\left(X_{j}-D_{j}\right)-e>p_{k}\left(X_{k}-D_{j}\right)-e
$$

where $p_{j} D_{j}=\left(1+r_{f}\right)(1-K)$, and the result follows.

\section{Proof of Proposition 3.}

Proposition 2 allows us to set $\alpha=1$ and focus on the permitted risky investments. Recall that the negative correlation assumption (assumption 5) implies an ordering of the monitoring capital threshold such that $K_{l}<, \ldots,<K_{j}<, \ldots,<K_{n}$ and that assumption 4 on minimum capital implies that $K_{1}>0$.

To prove part 1. For a level of capital $K \geq K_{n}$ equation (3.7) on market discipline is satisfied. Because of the negative correlation assumption $K>K_{j}, j=1, \ldots n-1$. Hence no shirking will occur. Thus bank's choice is among $n$ monitored investments. Lemma 2 states that asset class $n$ is chosen. To prove part 2. Because of the negative correlation assumption equation (3.7) is not satisfied for asset classes $j+1, \ldots, n$ while it is satisfied for asset classes $1, \ldots, j$. Part b) of assumptions 2 and 3 guarantee that if (3.7) is satisfied the bank has no incentive to shirk in assets with an index $\leq j$. Thus the bank will shirk for all asset classes $j+1$ to $n$ and will monitor investments in asset classes $1, \ldots, j$. Using Lemma 2 we know that $j$ is the bank's preferred choice among monitored assets. Recall that from assumption 1 all non-monitored investments in risky assets have negative expected value. Thus the best action for the regulator is to prohibit all assets $j+1, \ldots, n$. 
To prove part 3. For $0<K<K_{l}$, the set of monitored investments in risky asset classes is empty. Thus the best action for the regulator is to force the bank to invest in the safe asset only. This implies forbidding all risky assets and setting $\alpha=0$. 


\section{References}

Aggarwal, R. and K. T. Jaques (2001) "The Impact of FDICIA and prompt corrective action on bank capital and risk: Estimates using a simultaneous equations model" Journal of Banking and Finance 25, 1139-1160.

Aghion P. and P. Bolton (1997) “A Theory of Trickle-Down Growth and Development” Review of Economic Studies 64, 151-172.

Allen, F., E. Carletti, and R. Marquez (2005) "Credit market Competition and capital regulation" University of Maryland, Robert H. Smith School of Business, working paper n.06-037, September.

Barth, J. R., G. Caprio, R. Levine (2006) Rethinking Bank Regulation: Till Angels Govern. Cambridge and New York: Cambridge University Press.

Benston, J. G. and G. J. Kaufman (1997) "FDICIA after Five Years" Journal of Economic Perspectives 11, 139-158.

Besanko, D. and Kanatas, G. (1996) “The Regulation of Bank Capital: Do Capital Standards Promote Bank Safety?” Journal of Financial Intermediation 5, 160-183.

Berger, A. N., S. M. Davies, and M. J. Flannery (2000) "Comparing Market and Supervisory Assessments of Bank Performance: Who Knows What When?" Journal of Money Credit and Banking Vol. 32, No. 3, Part 2, August, 641-667.

Bhattacharya, S., M. Plank, G. Strobl, and J. Zechner (2002) "Bank Capital Regulation with Random Audits” Journal of Economic Dynamics and Control 26, 1301-1321. 
Biais, B, T. Mariotti, G. Plantin, and J-C. Rochet (2006) “Optimal Design and Dynamic Pricing of Securities" mimeo, IDEI Toulouse.

Calem, P. and R. Rob (1999) "The Impact of Capital-Based Regulation on Bank Risk-Taking" Journal of Financial Intermediation 8, 317-352.

Dewatripont, M. and J. Tirole (2004) The Prudential Regulation of Banks, MIT Press, Cambridge.

Elizalde, A. and R. Repullo (2006) "Economic and Regulatory Capital in Banking: What is the Difference?" mimeo July.

Flannery, M.J. and K.P. Rangan (2004) "Market forces at work in the banking industry: Evidence from the capital build up of the 1990s" mimeo, University of Florida.

Gorton, G. and A. Winton (2003) "Financial Intermediation" In: Costantinides, G. Harris, M., Stultz, R. (eds.) Handbook of the Economics of Finance. North-Holland, Amsterdam.

Helmann, T.F., K.C. Murdock, J.E. Stiglitz, (2000) Liberalization, moral hazard in banking, and prudential regulation: Are capital requirements enough?" American Economic Review 80, 11831200.

Holmström, B. and P. Milgrom (1991) "Multi-task principal-agent analysis: incentive contracts, asset ownership, and job design" Journal of Law, Economics and Organization 7 (special issue): 24-52. 
Holmström, B. and J. Tirole (1997) "Financial intermediation, loanable funds, and the real sector". Quarterly Journal of Economics 112: 663-692.

Jones, D.S. and K.K. King (1995) "The Implementation of prompt Corrective Action: An assessment" Journal of Banking and Finance 19, 491-510.

Kim, M., E.G. Kristiansen, and B. Vale (2005) "Endogenous product differentiation in credit markets: What do borrowers pay for? Journal of Banking and Finance 29, 681-699.

Kocherlakota, N. and I. Shim (2005) "Forbearance and prompt corrective action” BIS WP 177.

Peek, J., E.S. Rosengren, and G. M.B. Tootell (1999) "Is Bank supervision central to central banking?", Quarterly Journal of Economics 114,2, 629-653.

Pelizzon, L. and S. Schaefer (2005) "Pillar 1 vs Pillar 2 under Risk Management”, NBER wp 11666 October 2005.

Piketty, T. (1997) "The Dynamics of the Wealth Distribution and the Interest Rate with Credit Rationing” Review of Economic Studies 64, 173-189.

Rochet, J.C. (1992) "Capital requirements and the behaviour of commercial banks" European Economic Review. 36(5):1137-70.

Shim, I. (2004) “Dynamic Prudential Regulation: Is Prompt Corrective Action Optimal?” BIS WP.

Tirole, J. (2005) The Theory of Corporate Finance, MIT Press, Cambridge. 


\section{CESifo Working Paper Series}

for full list see www.cesifo-group.org/wp

(address: Poschingerstr. 5, 81679 Munich, Germany, office@cesifo.de)

2072 Marco Runkel and Guttorm Schjelderup, The Choice of Apportionment Factors under Formula Apportionment, August 2007

2073 Jay Pil Choi, Tying in Two-Sided Markets with Multi-Homing, August 2007

2074 Marcella Nicolini, Institutions and Offshoring Decision, August 2007

2075 Rainer Niemann, The Impact of Tax Uncertainty on Irreversible Investment, August 2007

2076 Nikitas Konstantinidis, Gradualism and Uncertainty in International Union Formation, August 2007

2077 Maria Bas and Ivan Ledezma, Market Access and the Evolution of within Plant Productivity in Chile, August 2007

2078 Friedrich Breyer and Stefan Hupfeld, On the Fairness of Early Retirement Provisions, August 2007

2079 Scott Alan Carson, Black and White Labor Market Outcomes in the $19^{\text {th }}$ Century American South, August 2007

2080 Christian Bauer, Paul De Grauwe and Stefan Reitz, Exchange Rates Dynamics in a Target Zone - A Heterogeneous Expectations Approach, August 2007

2081 Ana Rute Cardoso, Miguel Portela, Carla Sá and Fernando Alexandre, Demand for Higher Education Programs: The Impact of the Bologna Process, August 2007

2082 Christian Hopp and Axel Dreher, Do Differences in Institutional and Legal Environments Explain Cross-Country Variations in IPO Underpricing?, August 2007

2083 Hans-Werner Sinn, Pareto Optimality in the Extraction of Fossil Fuels and the Greenhouse Effect: A Note, August 2007

2084 Robert Fenge, Maximilian von Ehrlich and Matthias Wrede, Fiscal Competition, Convergence and Agglomeration, August 2007

2085 Volker Nitsch, Die Another Day: Duration in German Import Trade, August 2007

2086 Kam Ki Tang and Jie Zhang, Morbidity, Mortality, Health Expenditures and Annuitization, August 2007

2087 Hans-Werner Sinn, Public Policies against Global Warming, August 2007 
2088 Arti Grover, International Outsourcing and the Supply Side Productivity Determinants, September 2007

2089 M. Alejandra Cattaneo and Stefan C. Wolter, Are the Elderly a Threat to Educational Expenditures?, September 2007

2090 Ted Bergstrom, Rod Garratt and Damien Sheehan-Connor, One Chance in a Million: Altruism and the Bone Marrow Registry, September 2007

2091 Geraldo Cerqueiro, Hans Degryse and Steven Ongena, Rules versus Discretion in Loan Rate Setting, September 2007

2092 Henrik Jacobsen Kleven, Claus Thustrup Kreiner and Emmanuel Saez, The Optimal Income Taxation of Couples as a Multi-Dimensional Screening Problem, September 2007

2093 Michael Rauber and Heinrich W. Ursprung, Life Cycle and Cohort Productivity in Economic Research: The Case of Germany, September 2007

2094 David B. Audretsch, Oliver Falck and Stephan Heblich, It's All in Marshall: The Impact of External Economies on Regional Dynamics, September 2007

2095 Michael Binder and Christian J. Offermanns, International Investment Positions and Exchange Rate Dynamics: A Dynamic Panel Analysis, September 2007

2096 Louis N. Christofides and Amy Chen Peng, Real Wage Chronologies, September 2007

2097 Martin Kolmar and Andreas Wagener, Tax Competition with Formula Apportionment: The Interaction between Tax Base and Sharing Mechanism, September 2007

2098 Daniela Treutlein, What actually Happens to EU Directives in the Member States? - A Cross-Country Cross-Sector View on National Transposition Instruments, September 2007

2099 Emmanuel C. Mamatzakis, An Analysis of the Impact of Public Infrastructure on Productivity Performance of Mexican Industry, September 2007

2100 Gunther Schnabl and Andreas Hoffmann, Monetary Policy, Vagabonding Liquidity and Bursting Bubbles in New and Emerging Markets - An Overinvestment View, September 2007

2101 Panu Poutvaara, The Expansion of Higher Education and Time-Consistent Taxation, September 2007

2102 Marko Koethenbuerger and Ben Lockwood, Does Tax Competition Really Promote Growth?, September 2007

2103 M. Hashem Pesaran and Elisa Tosetti, Large Panels with Common Factors and Spatial Correlations, September 2007 
2104 Laszlo Goerke and Marco Runkel, Tax Evasion and Competition, September 2007

2105 Scott Alan Carson, Slave Prices, Geography and Insolation in $19^{\text {th }}$ Century AfricanAmerican Stature, September 2007

2106 Wolfram F. Richter, Efficient Tax Policy Ranks Education Higher than Saving, October 2007

2107 Jarko Fidrmuc and Roman Horváth, Volatility of Exchange Rates in Selected New EU Members: Evidence from Daily Data, October 2007

2108 Torben M. Andersen and Michael Svarer, Flexicurity - Labour Market Performance in Denmark, October 2007

2109 Jonathan P. Thomas and Tim Worrall, Limited Commitment Models of the Labor Market, October 2007

2110 Carlos Pestana Barros, Guglielmo Maria Caporale and Luis A. Gil-Alana, Identification of Segments of European Banks with a Latent Class Frontier Model, October 2007

2111 Felicitas Nowak-Lehmann D., Sebastian Vollmer and Immaculada Martínez-Zarzoso, Competitiveness - A Comparison of China and Mexico, October 2007

2112 Mark Mink, Jan P.A.M. Jacobs and Jakob de Haan, Measuring Synchronicity and Comovement of Business Cycles with an Application to the Euro Area, October 2007

2113 Ossip Hühnerbein and Tobias Seidel, Intra-regional Tax Competition and Economic Geography, October 2007

2114 Christian Keuschnigg, Exports, Foreign Direct Investment and the Costs of Corporate Taxation, October 2007

2115 Werner Bönte, Oliver Falck and Stephan Heblich, Demography and Innovative Entrepreneurship, October 2007

2116 Katrin Assenmacher-Wesche and M. Hashem Pesaran, Assessing Forecast Uncertainties in a VECX Model for Switzerland: An Exercise in Forecast Combination across Models and Observation Windows, October 2007

2117 Ben Lockwood, Voting, Lobbying, and the Decentralization Theorem, October 2007

2118 Andrea Ichino, Guido Schwerdt, Rudolf Winter-Ebmer and Josef Zweimüller, Too Old to Work, too Young to Retire?, October 2007

2119 Wolfgang Eggert, Tim Krieger and Volker Meier, Education, Unemployment and Migration, October 2007

2120 Stefan Napel and Mika Widgrén, The European Commission - Appointment, Preferences, and Institutional Relations, October 2007 
2121 Bertil Holmlund and Martin Söderström, Estimating Income Responses to Tax Changes: A Dynamic Panel Data Approach, October 2007

2122 Doina Maria Radulescu, From Separate Accounting to Formula Apportionment: Analysis in a Dynamic Framework, October 2007

2123 Jelle Brouwer, Richard Paap and Jean-Marie Viaene, The Trade and FDI Effects of EMU Enlargement, October 2007

2124 Kurt R. Brekke, Luigi Siciliani and Odd Rune Straume, Competition and Waiting Times in Hospital Markets, October 2007

2125 Alexis Direr, Flexible Life Annuities, October 2007

2126 Johannes Becker and Clemens Fuest, Quality versus Quantity - The Composition Effect of Corporate Taxation on Foreign Direct Investment, October 2007

2127 Balázs Égert, Real Convergence, Price Level Convergence and Inflation Differentials in Europe, October 2007

2128 Marko Koethenbuerger, Revisiting the "Decentralization Theorem” - On the Role of Externalities, October 2007

2129 Axel Dreher, Silvia Marchesi and James Raymond Vreeland, The Politics of IMF Forecasts, October 2007

2130 Andreas Knabe and Ronnie Schöb, Subsidizing Extra Jobs: Promoting Employment by Taming the Unions, October 2007

2131 Michel Beine and Bertrand Candelon, Liberalization and Stock Market Co-Movement between Emerging Economies, October 2007

2132 Dieter M. Urban, FDI Technology Spillovers and Wages, October 2007

2133 Valentina Bosetti, Carlo Carraro, Emanuele Massetti and Massimo Tavoni, Optimal Energy Investment and R\&D Strategies to Stabilise Greenhouse Gas Atmospheric Concentrations, October 2007

2134 David-Jan Jansen and Jakob de Haan, The Importance of Being Vigilant: Has ECB Communication Influenced Euro Area Inflation Expectations?, October 2007

2135 Oliver Falck, Heavyweights - The Impact of Large Businesses on Productivity Growth, October 2007

2136 Xavier Freixas and Bruno M. Parigi, Banking Regulation and Prompt Corrective Action, November 2007 